\title{
The Effect of Endometrial Thickness And Dominant Follicular Count on Intrauterine Insemination Cycles
}

\author{
${ }^{1}$ Foroughforghani, M.D, ${ }^{2}$ Azizeh Ghaseminegad,MD, ${ }^{3}$ Ezra Azmoodeh MD, \\ ${ }^{4}$ Jale Mohammad Pour MD, \\ ${ }^{l}$ Department Of Obstetrics And Gynecology, School Of Medicine Zabol University Of Medical Sciences, Zabol, \\ Iran Amiralmomenin Hospital, \\ ${ }^{2}$ Department Of Obstetrics And Gynecology School Of Medicine Zanan Hospital, Tehran University Of Medical \\ Sciences, Tehran, Iran. \\ ${ }^{3}$ Department Of Obstetrics And Gynecology School Of Medicine Zanan Hospital, Tehran University Of Medical \\ Sciences, Tehran, Iran \\ ${ }^{4}$ Department Of Obstetrics And Gynecology School Of Medicine Zanan Hospital, Tehran University Of Medical \\ Sciences, Tehran, Iran.
}

\begin{abstract}
:
Background: the size and number of the dominant follicle and the thickness of endometrium (ET) affect the pregnancy rate.

Objective: to evaluate the effect of endometrial thickness and dominant follicular count in intrauterine insemination cycles

Materials and Methods: 537 women between 20 and 44 years old in Zanan hospital Tehran, Iran were admitted. Subjects were undergoing COH-IUI during 2010 to 2011. Ovulation induction was started on patients who had criteria for COH IUI. When there was at least one dominant follicle ( $\geq 15)$, single IUI was performed after 36 hours of hCG injection.

Results: In 537 cycles of $\mathrm{COH}$ _IUI pregnancy occurred in 147 cases (\%27). In the no pregnant group ( $n=389)$, 136 women had dominant follicles greater than 3 and in the pregnant group $(n=148) 64$ women had dominant follicles greater than 3 and 84 women had less. In no pregnant $(n=389), 283$ women had ET greater than 7 and 106 cases had less. In the pregnant group $(n=148), 121$ cases had ET greater than and 27 cases had less 7.

Conclusion: we indicate that ovulation rate and pregnancy outcome were not different in IUI cycles when they are compared with regard to dominant follicular count and endometrial thickness.
\end{abstract}

Keywords: dominant follicular count, endometrial thickness, $\mathrm{COH}_{-} I U I$

\section{Introduction}

Controlled ovarian hyperstimulation $(\mathrm{COH})$ is effective in a number of clinical situations such as for the treatment of mild to moderate male factor infertility (if IUI alone is ineffective), surmountable pelvic factor infertility and unexplained infertility. The IUI component brings sperm close to the mature egg(s) in the fallopian tubes. The $\mathrm{COH}$ component often results in the simultaneous development of multiple mature eggs, which serve as "more targets" for the sperm $(1,2)$. However, previous reports have prepared conflicting information about the effects of addition OH to IUI in isolated cervical factor infertility and the additive effect of IUI to the ovulation induction in ovulatory dysfunction group (3).The most important issue in IUI procedure is the success rate of pregnancies in $\mathrm{OH} / \mathrm{IUI}$ cycles, so, suitable patients selection for this therapy will possibly increase the effectiveness. Furthermore, the timing and frequency of insemination are two further important factors that impact the success rates of IUI (4).Additionally, Several prognostic factors such as endometrial thickness, follicle number and size of the follicle, numbers of sperm inseminated, progressive motile sperm count, sperm morphology, female age, duration of infertility and infertility etiology have been related to the success of OH/IUI (5-9). Several studies have evaluated the effect of endometrial thickness on IUI, but the results are controversial (10-12). The endometrium is central, echogenic (detectable using ultrasound scanners), and has an average thickness of $6.7 \mathrm{~mm}$.During the menstrual cycle or estrous cycle, the endometrium grows to a thick, blood vessel-rich, glandular tissue layer. This represents an optimal environment for the implantation of a blastocyst upon its arrival in the uterus $(13,14)$.As mentioned in the previous paragraph the size and number of the dominant follicle and the thickness of endometrium (ET) affect the pregnancy rate. An experience by Belaisch-Allarty et al. indicated that endometrial thickness more than $10 \mathrm{~mm}$ increases the pregnancy rate (14). Additionally Esmailzadeh et al. signified that dominant follicles (size $\geq 16 \mathrm{~mm}, \mathrm{n}>2$ ) raise the pregnancy rate (15). We evaluated the Effect of endometrial thickness and dominant follicular count in intrauterine insemination cycles in this survey. 


\section{Materials and Methods}

537 women between 20 and 44 years old who were admitted to the infertility ward of Zanan Hospital, Tehran, Iran from 2010 to 2011 were enrolled in this clinical trial. Women were enrolled if they have at least one dominant follicle $\geq 15 \mathrm{~mm}$ and not at risk of OHSS (ovarian hyperstimulation) .on the other hand Patients were excluded if they have a history of OHSS, positive HIV serology, positive HBSAg serology, AUB (abnormal uterine bleeding), ovarian cyst, and active drug user. The committee of Tehran university of medical sciences approved the study protocol moreover the study were explained for all women and informed written consents were taken.

The demographic and anthropomorphic information as age, type of infertility (primary or secondary), duration of infertility, the cause of infertility such as polycystic ovary (PCO), tubal factor, male factor, endometriosis and unexplained infertility were evaluated on all women and recorded in the questionnaire. Ovulation induction was started on patients who had criteria for COH_IUI ( at least one dominant follicle $(\geq 15$ ), not at risk of OHSS) single IUI was performed after 36 hours of hCG injection.

On the day 3 of menstruation, all patients underwent vaginal ultrasound and induction of ovulation as the protocol of hospital designed was initiated. Clomiphene citrate (CC) was started on day 3 of the cycle. The starting dose of CC was $100 \mathrm{mg} /$ day for 5 days and continued with hMG (menogan ) on the day 7 for 3 days (one injection per day, intramuscular, IM)

On the day 12 , the ovarian response was monitored by vaginal ultrasound examination, when at least a follicle with the mean diameter $\geq 15 \mathrm{~mm}$ was observed, and then repeated every 1-2 days until follicle was $\geq 18$ $\mathrm{mm}$, at which time hCG (Pregnyl 10000 unit /IM ) was administrated as trigger of ovulation. After 36 hours, a single IUI was performed with $0.5 \mathrm{ml}$ fresh sperm wash medium.

Semen specimens were obtained by masturbation and collected for insemination within 1 hour of production. Sperms were washed using the gradient method with a supra-sperm medium for $20 \mathrm{~min}$, and then supra-sperm medium for $10 \mathrm{~min}$.

To confirm ovulation six days after hCG injection Serum progesterone was measured ( $\geq 3 \mathrm{ng} / \mathrm{ml}$ ), moreover 14 days after injection BhCG was measured to evaluate the pregnancy. To remove the possible positive effect, intercourse after the procedure was forbidden for the rest of the cycle in all women. Moreover, the luteal phase did not support by any medication. The primary outcomes of the trial were the occurrence of ovulation and pregnancy.

Statistical analysis

The data were entered on Statistical Package for the Social Sciences (SPSS) version 18 .0. The data were expressed as means SD and frequency $(\mathrm{N} \%)$ and the women's characteristics were compared using student $\mathrm{t}$-test and Chi-2. A value of $\mathrm{P}<0.05$ was considered statistically significant.

\section{Results}

Totally we evaluated 537 women mean age $28.50 \pm 5.26$ years. The pregnancy rate in 537 cycles of COH_IUI was $27 \%$ (147 women), in the non-pregnant group $(\mathrm{n}=389)$, there were no significant differences in the type or duration of infertility, mean age and the rate of pregnancy between the two groups(table1).136 cases had dominant follicles greater than 3 and in 253 cases the dominant follicles was less than 3. In pregnant group $(\mathrm{n}=148), 64$ cases had $\geq 3$ dominant follicles and 84 cases had less than 3 . the differences between two groups was not significant (Chi - square test, $\mathrm{p}=0.076)$. In non-pregnant women $(\mathrm{n}=389), 283$ cases had ET $\geq 7$ and 106 cases had less than 7. In pregnant group ( $\mathrm{n}=148) 121$ cases had $\mathrm{ET} \geq 7$ and 27 cases had under 7 . There were significant differences between two groups. (chi-square test, $\mathrm{p}=0.031$ ).(table 1 ).

Progesterone level $\geq 3 \mathrm{ng} / \mathrm{ml}$ at 6 days after hCG injection (as a sign of ovulation) were titrated. There were not statistical differences. (table 2). There was no difference between pregnant and no pregnant regarding cause of infertility and dominant follicle count and endometrial thickness, however in PCOS endometrial thickness had significant differences in the two groups (table 3,4).

\section{Discussion}

Intrauterine insemination (IUI) can be performed with or without controlled ovarian hyperstimulation $(\mathrm{COH})$ on the treatment of unexplained infertility, mild endometriosis, cervical hostility, anti-sperm antibodies and male sexual dysfunctions such as retrograde ejaculation, impotency, and hypospadias (16). pattern and thickness of endometrial during ovulatory cycles changes and after menstruation, the endometrium becomes thicker increasingly $(13,14)$. Previous experiences signified that maternal age, the number of preovulatory follicles, endometrial thickness, and motile sperms count are the predictors of pregnancy in women under IUI $(17,18)$. In current experience, we evaluated the effect of endometrial thickness and dominant follicular count on COH-IUI outcomes. The rate of pregnancy in our trial in 537 IUI cycles was $27 \%$ that was more than some previous studies such as Chosh et al trial that reported pregnancy rate about $22 \%$ on 1677IUI cycles (19) and Kamath et al survey that indicated The overall clinical pregnancy rate about $8.75 \%$ in their patients 
(20).However, the frequency of pregnancy in another study by Yousefi and Azargon was similar to our experience $(27 \%)(21)$. The reason for such a discrepancy is not clear, but it might be related to the heterogeneity in patient samples, treatment procedures, trial design, equipment, and techniques used in the IUI, and close attention should be paid to therapy parameters when reviewing and comparing these studies. In present experience, the endometrial thickness more than $7 \mathrm{~mm}$ in pregnant women was significantly higher than non-pregnant $(82.8 \%$ vs $72.8 \%, \mathrm{P}=0.03)$. In agreement with our findings, Esmaeelzade et al signified that the frequency of pregnancy positively correlated with the endometrial thickness (15). Moreover, another trial by Habibzadeh et al supported these results and indicated that the pregnancy rate in women with endometrial thickness more than $6 \mathrm{~mm}$ was higher than others (22). Additionally, we signified $43.2 \%$ of pregnant patients had dominant follicle more than three, however, the correlation between pregnancy rate and dominant follicle was not significant. Conversely, in a trial on 216 IUI cycles, the rate of pregnancy increased with dominant follicle (23). Furthermore, the meta-analyses on 11599 IUI cycles from 14 studies emphasized, when dominant follicles are more than 2, the chance of pregnancy increases. However, the rate of multiple pregnancies increased when the dominant follicles were more than 2 (24). This was an uncontrolled trial and we did not compare our results with control group moreover, we did not compare other fertility methods with COH-IUI technique. Further controlled investigations are recommended with to validate the findings reported here.

\section{Conclusions}

We signified dominant follicle more than 3 and ET $\geq 7 \mathrm{~mm}$ were not strongest predictive factors in IUI cycles, but in patients with PCOS, thickness of endometrium is the main factor

\section{Acknowledgment}

Hereby, we thank all our colleagues in infertility center of Zanan hospital Tehran for kindly technical assistance and there is no conflict of interest in this study.

\section{References}

[1]. Verhulst SM, Cohlen BJ, Hughes E, TeVelde E, Heineman MJ. Intra-uterine insemination for unexplained subfertility. Cochrane Database Syst Rev 2006;18:CD001838.

[2]. Duran HE, Morshedi M, Kruger T, Oehninger S. Intrauterine insemination: a systematic review on determinants of success. Hum Reprod Update 2002;8:373-384.

[3]. Steures P, van der Steeg JW, Hompes PG, Bossuyt PM, Habbema JD, EijkemansMJ ,etal.CECERM (Collaborative Effort for Clinical Evaluation in ReproductiveMedicine). Effectiveness of intrauterine insemination in subfertile couples with an isolated cervical factor: a randomized clinical trial. FertilSteril2007;88:1692-1696.

[4]. Dorjpurev U, Kuwahara A, Yano Y, Taniguchi T, Yamamoto Y, Suto A, et al. Effect of semen characteristics on pregnancy rate following intrauterine insemination. J Med Invest 2011; 58: 127-133.

[5]. Ibe'rico G, Vioque J, Ariza N, Lozano JM, Roca M, Lla'cer J, et al. Analysis of factors influencing pregnancy rates in homologous intrauterine insemination. FertilSteril2004;81:1308-1313.

[6]. Ghosh C, Buck G, Priore R, Wacktawski-Wende J, Severino M. Follicular response and pregnancy among infertile women undergoing

[7]. ovulation induction and intrauterine insemination. FertilSteril 2003; 80:328-335

[8]. 7.Steures P, van der Steeg JW, Mol BW, Eijkemans MJ, van der Veen F, Habbema JD, et al. CECERM (Collaborative Effort in Clinical

[9]. Evaluation in Reproductive Medicine). Prediction of an ongoing pregnancy after intrauterine insemination. FertilSteril2004;82:4551.

[10]. 8.Barros Delgadillo JC, Rojas Ruiz JC, Molina Munguı'a AC, Villalobos Acosta S, Sa'́nchezSolı's V, Barroso Villa G, et al. Prognostic factors of pregnancy in intrauterine insemination. GinecolObstet Mex 2006;74:611-625.

[11]. 9.Guven S, Gunalp GS, Tekin Y. Factors influencing pregnancy rates in intrauterine insemination cycles. J Reprod Med 2008;53: 257-265.

[12]. 10. ZahirZ.sharani S.H. Roshan Z. There was no statistically significant difference in pregnancy rate in three groups of endometrial thickness $(<7,714,>14)$. IRMS 2007; 12: 257-261.

[13]. 11.Doneness j.What of the imprication of myoma. Fertility .Sterility Hum Reprod 2002:14:24

[14]. 12.Day Baird D, Dunson DB, Hill MC, Cousins D, Schectman JM. High cumulative incidence of uterine leiomyoma in black and white women. Ultrasound evidence. Am j obstetGynecol 2003:188:100

[15]. 13.Dieterich C. Increased endometrial thickness on the day of HCC, injection does not adversely affect pregnancy. FertilSteril 2002; 77: 781 .

[16]. 14.De Geyter C, Schmitter M , De Gayter M , NieschlagE, Holzgreve W , Shnieder HP. Prospective evaluation of the ultrasound appearance of the endometrium in a cohort of 10186 infertile women. Fertile Steril 2000; 73:106

[17]. 15.Esmailzade s . and Faramarzim .Endometrial thickness and pregnancy outcome after intrauterine insemination. fertile sterile $2007 ;(88): 432-437$

[18]. 16.Aboulghar MA, Mansour RT, Serour GI, Al-Inany HG. Diagnosis and management of unexplained infertility: an update. Arch GynecolObstet 2003;

[19]. 267: 177-88.

[20]. 17. Zafar M, Jameel T, Abdullah KN. Impact of intrauterine insemination as first line treatment of subfertility. J Pak Med Assoc 2007; 57: 133-6.

[21]. 18.Zadehmodarres S, Oladi B, Saeedi S, Jahed F, Ashraf H. Intrauterine insemination with husband semen: an evaluation of pregnancy rate and factors affecting outcome. J Assist Reprod Genet 2009; 26: 7-11.

[22]. 19.Chosh C . Buck G,priore $R$, Wacktawski-wenda $\mathrm{j}$, severinoM.follicular response and pregnancy among infertile women undergoing ovulation induction and iui .fertile steril 2003;(80 ):328-335 . 
The Effect Of Endometrial Thickness And Dominant Follicular Count On Intrauterine Insemination Cycles

[23]. 20. Kamath MS, Bhave P, Aleyamma TK, Nair R, Chandy A, Mangalaraj AM, et al..Predictive factors for pregnancy after intrauterine insemination: A prospective study of factors affecting outcome. J Hum Reprod Sci. 2010 Sep-Dec; 3(3): 129-134

[24]. 21.Yousefi B, AzargonA.Predictive factors of intrauterine insemination success of women with infertility over 10 years. JPMA.2011; 61:165-68

[25]. 22.Habibzadeh V, NematolahiMahani SD, Kamyab H, The correlation of factors affecting the endometrial thickness with pregnancy outcome in the IUI cycles. I J R M .2011;9(1): 41-46

[26]. 23. Van RumsteMU,Custe-Im. Hum Reprod update $2008 ; 14$ (6); 563-70

[27]. 24-Kolibianakis EM ,ZikopouluskA.Fatemi HM .Center for Reproductive Medicine Dutch -speaking .Reprod Biomed online 2004;8 (1 );115-8

Table 1: comparison of pregnant and nonpregnant women regarding age, duration of infertility, follicular dominant count, and endometrial thickness

\begin{tabular}{|c|c|c|c|c|}
\hline & & \multicolumn{2}{|l|}{ BhCG } & \multirow[t]{2}{*}{$\mathrm{P}$} \\
\hline & & positive & negative & \\
\hline \multicolumn{2}{|l|}{ Age $($ mean \pm SD $)$} & $28.16 \pm 4.86$ & $28.87 \pm 5.61$ & 0.14 \\
\hline \multicolumn{2}{|l|}{ Duration of infertility(mean \pm SD) } & $4.3 \pm 3.2$ & $4.7 \pm 3.7$ & 0.22 \\
\hline \multirow[t]{2}{*}{ Dominant follicles } & $<3$ & $84(56.8 \%)$ & $253(65 \%)$ & \multirow[t]{2}{*}{0.07} \\
\hline & $>3$ & $64(43.2 \%)$ & $136(35 \%)$ & \\
\hline \multirow[t]{2}{*}{ Endometrial thickness } & $<7$ & $27(18.2 \%)$ & $106(27 \%)$ & \multirow[t]{2}{*}{0.03} \\
\hline & $>7$ & $121(81.8 \%)$ & $283(72.8 \%)$ & \\
\hline
\end{tabular}

Table 2: comparison of follicular dominant count and endometrial thickness in women with Progesterone level $(3 \mathrm{ng} / \mathrm{ml})$.

\begin{tabular}{|l|l|l|l|l|}
\hline \multicolumn{2}{|c|}{} & $\mathrm{P} 4<3$ & $\mathrm{P} 4>3$ & $\mathrm{P}$ \\
\hline \multirow{2}{*}{ Dominant follicles } & $<3$ & $12(0.74 \%)$ & $166(93.26 \%)$ & \multirow{2}{*}{0.16} \\
\cline { 2 - 4 } & $>3$ & $13(11.4 \%)$ & $101(88.6 \%)$ & \\
\hline \multirow{2}{*}{ Endometrial thickness } & $<7$ & $5(6.94 \%)$ & $67(93.06 \%)$ & 0.57 \\
\cline { 2 - 4 } & $>7$ & $20(9.1 \%)$ & $200(90.9 \%)$ & \\
\hline
\end{tabular}

Table3; pregnancy rate, dominant follicular counts and infertility type

\begin{tabular}{|c|c|c|c|c|}
\hline \multicolumn{2}{|l|}{ infertility } & \multicolumn{2}{|c|}{ Dominant follicles } & \multirow[t]{2}{*}{$P$} \\
\hline & & $>3$ & $<3$ & \\
\hline \multirow[t]{2}{*}{$\mathrm{PCO}$} & BhCG+ & $18(30.0 \%)$ & $25(23.4 \%)$ & \multirow[t]{2}{*}{0.34} \\
\hline & BhCG- & $42(70.0 \%)$ & $82(76.6 \%)$ & \\
\hline \multirow[t]{2}{*}{ Male factor } & BhCG+ & $8(30.8 \%)$ & $13(21 \%)$ & \multirow[t]{2}{*}{0.32} \\
\hline & BhCG- & $18(69.2 \%)$ & $49(79 \%)$ & \\
\hline \multirow[t]{2}{*}{ Tubal } & BhCG+ & $7(31.8 \%)$ & $7(18.4 \%)$ & \multirow[t]{2}{*}{0.23} \\
\hline & BhCG- & $15(68.2 \%)$ & $31(81.6 \%)$ & \\
\hline \multirow[t]{2}{*}{ Endometriosis } & BhCG+ & $3(50 \%)$ & $8(50 \%)$ & \multirow[b]{2}{*}{-} \\
\hline & BhCG- & $3(50 \%)$ & $8(50 \%)$ & \\
\hline \multirow[t]{2}{*}{ Unexplained } & BhCG+ & $28(32.6 \%)$ & $31(27.2 \%)$ & \multirow[t]{2}{*}{0.41} \\
\hline & BhCG- & $58(67.4 \%)$ & $83(72.8 \%)$ & \\
\hline
\end{tabular}

Table4; pregnancy rate, Endometrial thickness and infertility type

\begin{tabular}{|c|c|c|c|c|}
\hline \multicolumn{2}{|l|}{ infertility } & \multicolumn{2}{|c|}{ Endometrial thickness } & \multirow[t]{2}{*}{$\mathrm{P}$} \\
\hline & & $>7$ & $<7$ & \\
\hline \multirow[t]{2}{*}{$\mathrm{PCO}$} & BhCG+ & $38(29.9 \%)$ & $5(5.12 \%)$ & \multirow[t]{2}{*}{0.28} \\
\hline & BhCG- & $89(70.0 \%)$ & $35(78.5 \%)$ & \\
\hline \multirow[t]{2}{*}{ Male factor } & BhCG+ & $14(26.4 \%)$ & $7(20 \%)$ & \multirow[t]{2}{*}{0.49} \\
\hline & BhCG- & $39(73.6 \%)$ & $28(80 \%)$ & \\
\hline \multirow[t]{2}{*}{ Tubal } & BhCG+ & $7(31.8 \%)$ & $3(31.2 \%)$ & \multirow[t]{2}{*}{0.84} \\
\hline & BhCG- & $15(68.2 \%)$ & $11(67.8 \%)$ & \\
\hline \multirow[t]{2}{*}{ Endometriosis } & BhCG+ & $6(46 \%)$ & $5(65.5 \%)$ & \multirow[b]{2}{*}{0.5} \\
\hline & BhCG- & $7(54 \%)$ & $4(44.5 \%)$ & \\
\hline \multirow[t]{2}{*}{ Unexplained } & BhCG+ & $52(31.5 \%)$ & $7(20 \%)$ & \multirow[t]{2}{*}{0.17} \\
\hline & BhCG- & $113(80 \%)$ & $28(80 \%)$ & \\
\hline
\end{tabular}

